\title{
Three Dimensional Numerical Simulation for the Effect of Quasi-DC Plasma on Ethylene-Air Jet Flow In Scramjet Combustor
}

\author{
Zhi Zheng ${ }^{\mathrm{a}}$, Wansheng $\mathrm{Nie}^{\mathrm{b}}$, Xueke Che ${ }^{\mathrm{c}}$, Jinlong $\mathrm{Li}^{\mathrm{d}}$, Zheng Zhang ${ }^{\mathrm{e}}$ and \\ Siyin Zhou ${ }^{\dagger}$
}

Department of Space Equipment, Equipment Academy, Beijing 101416, China

adymzz1166@163.com, bnws1969@126.com, 'chedk@163.com, dklee111@mail.nwpu.edu.cn, egeneral_zz@163.com, friyin@163.com

Keywords: numerical simulation, quasi-DC plasma, scramjet combustor, flow field.

\begin{abstract}
To study the effect of quasi-DC discharge plasma on the cold flow field, under the low equivalent ratio of ethylene and air in the combustor of scramjet, a quasi-DC discharge plasma model crossed the front wall of the cavity has been settled. Under the different plasma actuation intensity, the effect of plasma on combustion chamber temperature, pressure distribution, cavity drag force characteristics and mass exchange rate of the cavity are numerically studied. The results showed that, the quasi-DC plasma improved the temperature in the cavity obviously. Due to the plasma "cutting" effect on the shear layer, the impact of the shear layer on the rear edge of the cavity has been weakened. With the increasing of the plasma actuation intensity, the drag force of the cavity decreases slightly, meanwhile, the mass exchange rate of the cavity increases remarkably.
\end{abstract}

\section{Introduction}

Scramjet engine is the main propelling equipment of hypersonic vehicle. Because of the complication of working environment and challenges of fuel mixing, ignition, stable combustion, cooling, how to quickly fire in the supersonic jet and to stabilize the combustion has been the key technology [1]. Cavity, integrating the function of fuel injection, mixing enhancement and stable flame, is an effective equipment of combustion supporting and flame holding [2,3], which is widely used in various aerospace vehicles. However, the cavity can only work well in designed operating condition, but its performance was limited in undersigned condition.

In recent years, plasma flow control, ignition and auxiliary firing were regarded as frontier technology and have got extensive attention $[4,5]$. In 1981, Kimura et al. attempted to use plasma torch to improve the ignitability in supersonic flow [6]. Takita et al. [7, 8] used plasma torch to ignite different kinds of fuel in supersonic flow under different Mach number successfully and they found the combustion efficient was improved by this way. By using high power plasma ignition, under the situation when $\mathrm{Ma}=2$, Wenyan Song et al. fired kerosene directly instead of having to light other fuel to make ignition easier [9]. Fei Li et al. [10] use the plasma ignite kerosene jet in supersonic flow. The Experimental results show that the plasma enhancing the mixture of kerosene and air within a limited area is a very important factor to ignition.

According to the range of quasi-DC discharge plasma actuation intensity, the plasma actuation intensity could be expressed by the temperature value Tp. Four actuation intensity of $\mathrm{OK}$ (no plasma situation), $2000 \mathrm{~K}, 2500 \mathrm{~K}$ and $3000 \mathrm{~K}$ had been calculated respectively with five plasma actuators turned on simultaneously in the combustor. Under the different plasma actuation intensity, the effect of plasma on combustion chamber temperature, pressure distribution, cavity drag force characteristics and mass exchange rate of the cavity are numerically studied by using 3-d simulation.

\section{Computational model}

The scramjet engine model used in this article can reference Fig.1. Combustion chamber (the height is $33.064 \mathrm{~mm}$, the width is $44 \mathrm{~mm}$ ) entrance located at $\mathrm{X}=0 \mathrm{~mm}$. The whole superior wall keeps $1^{\circ}$ 
divergence angle to avoid thermal blocking. Using single nozzle to eliminating the effect of nozzle position and quantity. The exit boundary located at downstream which is $60 \mathrm{~mm}$ far from the entrance of combustion chamber. The detail parameters of the mesh and partition method, governing equations, physical models, quasi-DC plasma model, kinetic model and boundary conditions can be found in reference [11].

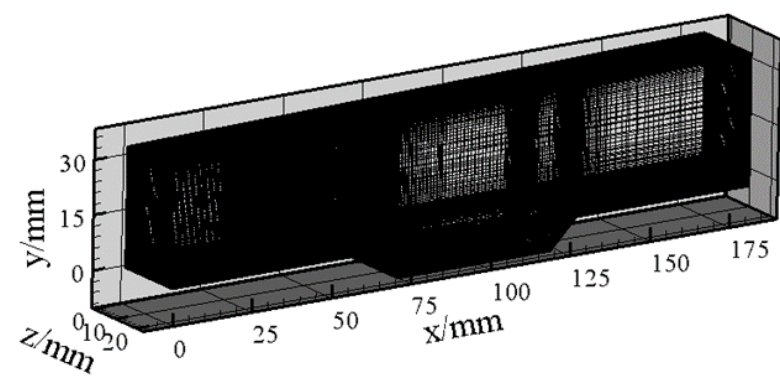

Fig.1 Mesh of computational zone

\section{Results and Discussion}

\subsection{Effect of plasma on combustion chamber temperature}

Fig. 2 shows the temperature distribution of the symmetry surface, cavity and rear wall of the combustion chamber under four kinds of actuation intensities. Compared with the temperature field without plasma, the distribution of combustor temperature had been influenced obviously with the plasma.

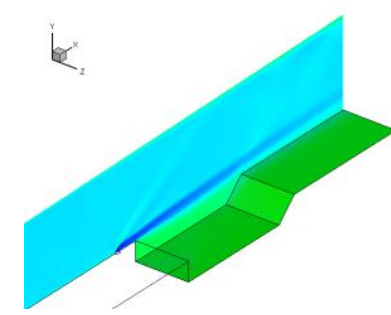

(a)

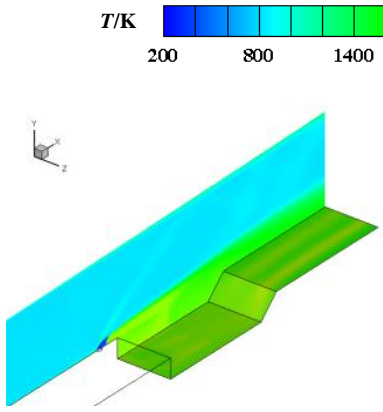

(b)

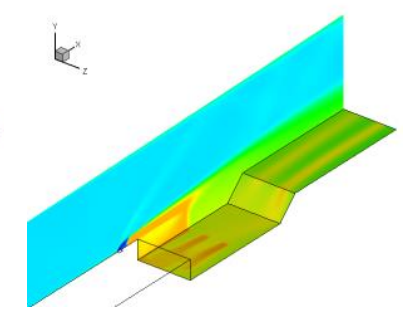

(c)

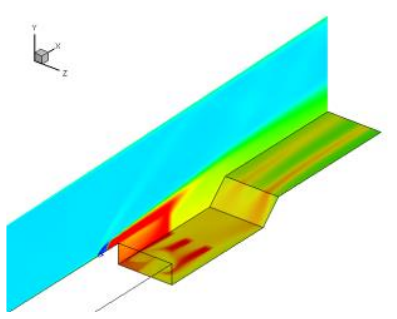

(d)

(a) $0 \mathrm{~K}$ (no plasma) (b) $2000 \mathrm{~K}$ (c) $2500 \mathrm{~K}$ (d) $3000 \mathrm{~K}$

Fig. 2 The distribution of temperature in the combustor:

Without plasma, a narrow strip of low temperature due to the fuel jet can be observed clearly in the symmetry plane of the combustion chamber, the high temperature region in the flow field is mainly located in the inner cavity and the rear wall of combustion chamber, and the wall temperature distribution is uniform. When the excitation intensity Tp is $2000 \mathrm{~K}$, the low temperature zone of fuel jet on the symmetrical surface is shortened obviously, the high temperature zone of the combustion chamber is integrally raised, the temperature of the cavity slope wall and rear wall of the combustion chamber is improved. However, due to the little difference between the Tp and mean temperature of the cavity, the effect of plasma on the cavity temperature is cloudy. With the actuation intensity increased to $2500 \mathrm{~K}$ and $3000 \mathrm{~K}$, the high temperature region in front of the cavity gradually clear, mean temperature of cavity temperature gradually increased, a high temperature strip appeared in the cavity slope wall and back wall of the combustor.

Table 1 . The mean temperature of the whole combustor and the rear wall of cavity

\begin{tabular}{ccc}
\hline Actuation & Mean temperature of the & Mean temperature on the rear wall of \\
combustor(K) & cavity $(\mathrm{K})$ \\
\hline (ntensity $(\mathrm{K})$ & 878.50 & 1503.92 \\
2000 & 903.848 & 1957.008 \\
2500 & 910.2891 & 2194.0146 \\
3000 & 914.03 & 2332.453 \\
\hline
\end{tabular}


Table 1 lists the calculated temperature of the combustion chamber and cavity wall temperature under the different actuation intensity. From the table we can see that with the increase of the actuation intensity, the whole combustion chamber temperature increased, but the average temperature increment between each actuation intensity decreased. Compared to the no plasma, the cavity wall temperature increased significantly.

\subsection{Effect of plasma on pressure at front and rear edge of cavity}

Fig.3 (a) and (b) show the wall pressure distribution near the front and rear edge of the cavity in the symmetry plane $(\mathrm{z}=0)$ of the combustion chamber at different plasma actuation intensities, where the pressure has been no normalized by the inflow static pressure. The plasma action area starts at $64 \mathrm{~mm}$, in Fig. 2 (a), before $x=62 \mathrm{~mm}$, the pressure curve shows a trend of increasing at first and then decreasing rapidly due to the impact of the shock wave formed by the fuel jet. When the plasma exists, the minimum pressure increases with the enhancement of the actuation intensity. The main reason for this phenomenon is that the plasma filament at $64 \mathrm{~mm}$ induces an oblique shock wave, which increased the local pressure, and the higher the actuation intensity, the stronger effect the plasma frontier region by the induced wave. Between the $62 \mathrm{~mm}-67.5 \mathrm{~mm}$, the pressure curve rise rapidly, due to the induced shock wave generated by the plasma, the peak value of the pressure curve is only slightly increased with higher actuation intensity. After $67.5 \mathrm{~mm}$, due to the shock wave system induced by the plasma, the velocity of inflow at the front edge of the cavity is reduced which is higher in no plasma situation. This changes the wave structure of leading edge, which makes the pressure curve more gradual as the intensity of the actuation increases.

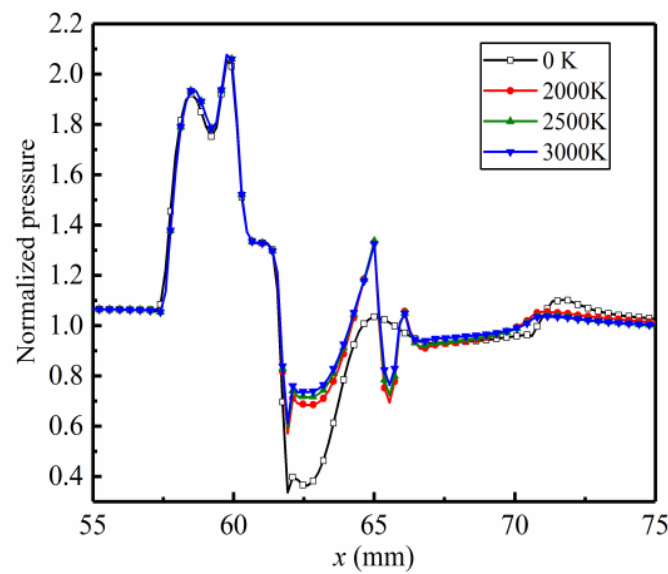

(a)

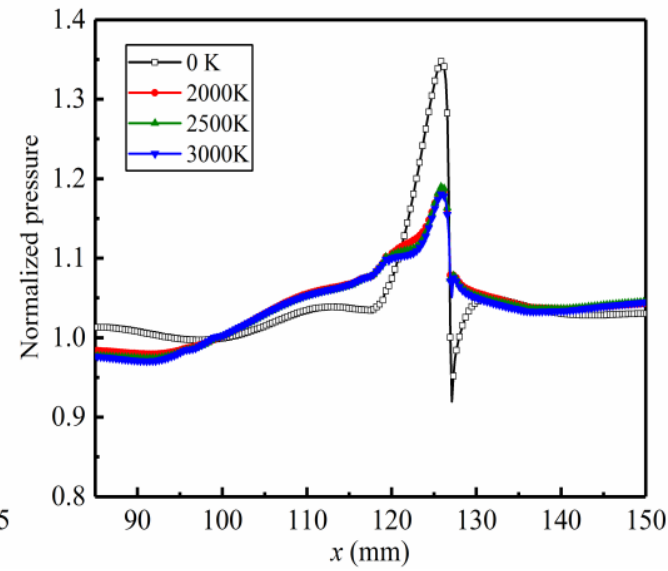

(b)

Fig.3 Wall pressure distribution near the rear edge of the cavity: (a) front edge (b) rear edge

As shown in Fig. 2 (b), the peak pressure at the rear edge of the cavity decreases with the action of the plasma. Compared with no plasma, the peak value of pressure is about $15 \%$ down, and the higher the actuation intensity, the lower the peak value of pressure. This is because the plasma filament passes through the cavity shear layer, under the plasma thermal and blocking mechanism, changes the original flow field near the shear layer, and weakens the diffusion of the fluid in the shear layer to the downstream, meanwhile, the shear layer is lifted due to temperature increasing in the cavity induced by plasma, the multiple effects lightened the impact of the original shear layer on the rear wall of the cavity and resulted in a decrease of the pressure peak.

\subsection{Analysis of cavity drag force characteristics}

For a equal section combustion chamber, the chamber drag force is mainly caused by the cavity, which including pressure drag and friction resistance. Considering the two forces, the pressure drag is equal to the force difference among the front and rear wall in cavity. Compared with pressure drag, friction resistance is very small and can be neglected. Thus, the pressure drag will be treated as the cavity drag here. The calculation results of the drag force of the front and rear walls of the cavity are shown in Table 2; The definition of drag coefficient can be found in [3]. 
Table 2. Drag parameters of the cavity

\begin{tabular}{ccccc}
\hline $\begin{array}{c}\text { Actuation } \\
\text { intensity }(\mathrm{K})\end{array}$ & $\begin{array}{c}\text { Force of front } \\
\text { wall }(\mathrm{N})\end{array}$ & $\begin{array}{c}\text { Force of rear } \\
\text { wall }(\mathrm{N})\end{array}$ & $\begin{array}{c}\text { Drag } \\
\text { force }(\mathrm{N})\end{array}$ & $\begin{array}{c}\text { Drag } \\
\text { coefficient }\end{array}$ \\
\hline 0(no plasma) & 17.98 & 32.76 & 14.77 & 0.05951 \\
2000 & 18.03 & 32.70 & 14.67 & 0.00591 \\
2500 & 17.95 & 32.69 & 14.75 & 0.00594 \\
3000 & 17.94 & 32.39 & 14.45 & 0.05823 \\
\hline
\end{tabular}

As can be seen from table 2, under the equivalence ratio studied in this paper, quasi DC discharge plasma reduces the drag force produced by ethylene and air flow at the rear wall of the cavity. With the increase of plasma actuation intensity, the drag coefficient decreases. Compared with the time without opening the plasma actuator, the cavity drag force decreased slightly. According to the previous analysis, the plasma reduces the impact strength of the shear layer on the rear wall of the cavity and leads to the reduction of the cavity resistance.

\subsection{Analysis of cavity mass exchange characteristics}

The mass exchange rate of the cavity is the mass of the main fluid being sucked into the cavity per unit time. The mass exchange is mainly carried out by the falling vortex generated in the shear layer, which effectively sucked the inner components of the cavity and carried away by convection of mainstream, a rapid flow can take more mass of fluid at the same time.

Table 3. Drag parameters of the cavity

\begin{tabular}{cccc}
\hline Actuation intensity/K & Mass exchange rate $(\mathrm{g} / \mathrm{s})$ & Actuation intensity/K & Mass exchange rate $(\mathrm{g} / \mathrm{s})$ \\
\hline O(no plasma) & 17.9897 & 2500 & 17.95 \\
2000 & 18.0312 & 3000 & 17.94 \\
\hline
\end{tabular}

As the shear layer covers above the cavity, the mass exchange rate could be calculated by monitoring the inlet and outlet flow through the cavity osculum. The calculated mass exchange rate for the cavity under four actuation intensities is shown in Table 3. Compared to the case where the plasma actuator is not turned on, after the actuator is turned on, the mass exchange rates of the cavities increased by $139 \%, 624 \%, 743 \%$, respectively. The thermal effect of the plasma promotes the external diffusion of the mass inside and outside the cavity and accelerates the mass exchange of the cavity, so more fuel will be sucked into the cavity to improve the mixing of the ethylene and air. In terms of the improvement of the efficiency of the cavity exchange rate, with the increase of the plasma actuation intensity, the efficiency of the mass exchange rate between each actuation intensity increases first and then decreases.

\section{Conclusion}

This article analyzes the influence of quasi-DC discharge plasma to scramjet combustor cold flow field. Compared the difference of temperature flow field of combustion chamber, the front edge and rear edge of cavity's pressure field, cavity obstruction and cavity mass exchange rates under the different plasma actuation intensity. The main conclusions are as follows:

1) Due to the high temperature character, plasma can change the temperature distribution of combustion chamber, and increase the average temperature in cavity.

2) The induced shock wave and its cutting function created by plasma can weaken the shock wave at cavity's leading and trailing edges, lift the shear layer and decrease the impinging pressure to rear edge of cavity by $15 \%$.

3) The higher intensity of the plasma actuation is, the lesser of the peak value of the impinging pressure the rear edge get.

4) Under the equivalence ratio analyzed in this article, plasma decreases the drag force of the cold flow of the cavity weakly. As long with the increasing of intensity of the plasma actuation, the mass exchange rate of cavity getting higher. 


\section{References}

[1] Billig F S. Research on supersonic combustion [J]. J Propuls Power, 1993, NO.9, p. 499-514.

[2] Bai Chao. The influence of cavity configuration on supersonic flow and combustion process [D]. Tianjin: Hebei University of Technology, 2012. p. 3

[3] Sun Mingbo. Studies on flow patterns and flame holding mechanisms of cavity flame holders in supersonic flows [D]. Changsha: National University of Defense Technology, 2008. p. 12

[4] Li Yinghong. Progress in research of plasma-assisted flow control, ignition and combustion [J]. High Voltage Engineering, Vol. 40 (2014) No. 7, p. 2024-2038.

[5] He Liming, Liu Xingjian, Zhao Bingbing, et al. Current investigation progress of plasma -assisted ignition and combustion [J]. Journal of Aerospace Power, Vol.31 (2016) No.7, p.1537-1551.

[6] Kimura I, Aoki H, Kato M. The use of a plasma jet for flame stabilization and promotion of combustion in supersonic air flows [J]. Combustion \& Flame, Vol. 42 (1981) No. 3, p. 297-305.

[7] Takita K, Moriwaki A, Kitagawa T, et al. Ignition and flameholding of $\mathrm{H} 2$ and $\mathrm{CH} 4$ in high temperature airflow by a plasma torch [J]. Combustion \& Flame, Vol.132 (2003) No.4, p.679-689.

[8] Takita K, Ohashi R, Abe N. Suitability of C2-, C3-hydrocarbon fuels for plasma ignition in high -speed flow [J]. Journal of Propulsion \& Power, Vol. 25 (2009) No.3, p. 565-570.

[9] Song Yanwen, Liu Weixiong, He Wei, et al. Experimental investigation of plas ma ignition in supersonic combustor [J]. Journal of Experiments in Fluid Mechanics, Vol. 20 (2006) No.4, p. 20-24

[10] Li Fei, Yu Xilong, Gu Hongbin, et al. Experiment on kerosene fueled scramjet ignition by using plasma torch [J]. Journal of Aerospace Power, Vol. 27 (2012) No.4, p.824-831.

[11] Zheng Zhi, Nie Wansheng, Zhang Zheng et al. Effect of pulsed plasma on fuel jet in scramjet cavity [J]. Infrared and Laser Engineering, Vol.46 (2017) No.2, p. 0239005 